\title{
EL CONCEPTO DE DILECTIO EN LA NOVELA FRANCESA
}

\section{Ma del Carmen FERNÁNDEZ DÍAZ}

Facultad de Humanidades de Lugo

Universidad de Santiago de Compostela

En 1878, el abad Jean Grange denunciaba "la terrible cantidad de escritos envenenados que la clase popular devora cada día" 1 . Hacía referencia el clérigo a las edulcoradas novelas románticas que eran leídas sobre todo por las jóvenes. Y es que el descubrimiento de la sensibilidad que comenzó a encumbrarse a partir de 1750 no podía sino contribuir a un aumento considerable de los relatos que describían estados de ánimo singulares.

Ya Fénelon, en pleno siglo XVII, había entrevisto el peligro en su Tratado sobre la educación de las jóvenes (1687), en el que afirmaba: Las jóvenes se apasionan por las novelas...en las que se mezcla el amor profano. Se vuelven visionarias al acostumbrarse al lenguaje de los héroes novelescos; se echan a perder para la vida, ya que todos esos hermosos sentimientos, esas pasiones generosas, esas aventuras que el autor ha inventado no tienen relación alguna con la realidad cotidiana ${ }^{2}$.

La Iglesia sentía inquietud por poner freno a todo exceso de fantasía, al encumbramiento del amor terrenal que propugnaba el género novelesco, y proponía la idea de una felicidad que debía situarse, a través de las criaturas, exclusivamente en Dios. $\mathrm{Su}$ ideal era, a este respecto, la dilectio, el amor mesurado, matrimonial y debidamente reglado.

Pero, frente a esta postura, la literatura francesa se había embarcado desde antiguo en otra aventura: la de describir la fuerza arrolladora de la pasión, del eros. Esta tendencia erótica que tanto preocupaba a los moralistas del siglo XIX puede rastrearse desde la Edad Media, incluso en el amor cantado por los trovadores que, a través de sus hermosísimas composiciones, lamentan la desdicha de no poder acceder a la plenitud de la vivencia real que tantas veces imaginan.

El teórico del amor cortés, André le Chapelain, describió fielmente en su obra De l'amour (1186-1190) el concepto de dilectio, que pronto se convertirá en la propuesta única de los teólogos. Decía Le Chapelain que la dilectio es el sentimiento moderado que existe entre los esposos, el amor conyugal, lícito, que poco tiene que ver con el heterodoxo concepto de amor; es decir, con el deseo sexual que inevitablemente se conjuga con la ternura, la dulzura e incluso el agradecimiento. Y este último amor remonta directamente al eros griego, liberado de compromisos e instituciones, irreverente con los conceptos de pecado y de falta que acuñaron algunos dogmas religiosos $y$, en consecuencia, la sociedad civil ${ }^{3}$.

La institución matrimonial tal como hoy la entendemos fue una creación del cris-

\footnotetext{
${ }^{1}$ Opinión publicada en "L'Ouvrier" (16-2-1878), revista católica. El artículo reproduce la intervención del abad en un Congreso eclesiástico celebrado en Lyon a finales a 1877.

${ }^{2}$ Fénelon, Traité de l'éducation des filles, cap.II.

${ }^{3}$ M. Zink, Introduction à la literature française du Moyen Age, Paris (Livre de Poche) 1933.
} 
tianismo, pero conviene no olvidar que las formas de unión heterosexual anteriores poco tenían que ver con la idea de indisolubilidad que la nueva religión impuso. Al tiempo, la Iglesia también introdujo su propia concepción de la sexualidad, proclamando el estricto control sobre el deseo y el placer ${ }^{4}$.

A raíz de estos cambios se produjo un continuo vaivén a lo largo de los siglos entre dilectio y amor, entre razón y pasión. La óptica será cambiante, según el encuadre ideológico del autor y la época a la que pertenezca. Sea como fuere, desde los primeros textos franceses en lengua vernácula, asistimos al esfuerzo por domeñar y canalizar la pasión, aunque el objetivo soñado, el que se manifiesta raras veces de manera directa y clara, la meta a alcanzar tras las duras pruebas a las que voluntariamente se somete el amante sea siempre el de la unión física, efectiva y real. Tal es el trasfondo del amor cortés y también el que, bajo múltiples velos, se oculta en relatos de autores tan píos como pudo serlo Marguerite de Navarre, en pleno Renacimiento.

Directa y plenamente imbuida por el neoplatonismo, la reina de Navarra no puede ocultar en su Heptamerón (1588) la merma que dicha teoría opera en el tejido amoroso, tendiendo a reducir a lo emocional la complejidad del encuentro entre géneros. Por eso, en los diferentes relatos de su libro, repleto de amores trágicos y dolorosos, se perfila el erotismo, la pasión intensa y poderosa incluso frente a la razón y la voluntad.

Es, lógicamente, este tipo de sentimiento el que los teólogos denuncian. Frente a él propondrán valores tales como la honestidad, el pudor, la modestia o la discreción. El neoplatonismo, a su manera, también los establece, pero Marguerite de Navarre, en su intento por denunciar los excesos a los que conduce la pasión, no consigue otra cosa que confirmar la violencia primera del sentimiento y los desmanes y funestas consecuencias a las que, en ocasiones, conduce.

Es preciso recordar que la doble moral que se instauró en Occidente daba prioridad al cumplimiento de los deseos masculinos, pero no reconocía semejante liberalidad en el caso de las mujeres. Precisamente a ellas se dedicaban las advertencias, previniéndolas contra las temibles consecuencias que sus naturales inclinaciones podían acarrearles. Ese será también el objetivo de la posterior novela católica, la necesidad perentoria de domesticar las pulsiones femeninas, presente ya desde la Edad Media, pero bastante más elocuente a medida que avance el tiempo.

En la novela francesa del siglo XVII, observamos que los protagonistas ofrecen a sus damas una auténtica panoplia de gestos heroicos y gloriosos. Se trata del género galante, de origen cortés, y de carácter moderado y discreto. Ahora bien, tras esa pose, se oculta el sueño de la recompensa anhelada, la misma en todo caso a la que ya aspiraban los trovadores. Honoré d'Urfé codificó en su Astrée (novela en cinco partes cuya publicación abarca desde 1607 hasta 1627) las notas dominantes de lo que entonces se llamaba "una honesta amistad": Celadon convierte a su amada Astrée en un auténtico ídolo, le rinde devoción, pero esa sublimación amorosa apenas puede encubrir una adoración sensual que tiende hacia la satisfacción pura y simple del deseo.

\footnotetext{
${ }^{4}$ J. Goody, La familia europea, Barcelona (Ed. Crítica) 2001, p.55.
} 
Genette supo interpretar acertadamente el meollo de una historia, en apariencia, tan edulcorada. Observa el crítico la persistencia del platonismo en la obra y también la de la cortesía medieval, pero desvela que el fin perseguido se aleja del meramente contemplativo 5 . Lo que Maurice Lever denomina "teología del amor"6 recubre otro interés difícilmente camuflable. Se trata de un erotismo devoto que tendrá su contrapunto a inicios del siglo ilustrado en una de las novelas más audaces por su realismo y, a la vez, más aleccionadoras por su desenlace. Nos referimos a Manon Lescaut (1731), que podríamos definir como la anti-novela galante, la que echa por tierra la quimera de un ascenso gradual y meritorio del enamorado, tal como en su momento había propuesto Dante. Si, desde entonces, se tuvo en consideración este camino de perfección íntima y espiritual a través de las dificultades, Manon será quien lo destrone: Des Grieux, el protagonista, desciende a los infiernos, sin que eso le asegure la recompensa del amor.

El desfallecimiento interior también está presente en Julie ou la Nouvelle Héloïse (1761), del muy sensible Rousseau, que curiosamente querían proponer a través de sus páginas el valor de la virtud. Resistir a la pasión, no permitir que su empuje arrastre hacia el abismo no significa necesariamente que la fuerza de las emociones quede enmascarada. Muy al contrario, Rousseau desvela el supremo esfuerzo de voluntad que ha de llevarse a cabo y las desastrosas consecuencias que esa virtud necesaria, que observamos en Julie, conlleva.

Las normas morales propuestas por los teólogos son fácilmente perceptibles en Julie, mujer casada contra su voluntad, pero resuelta a mantenerse en los límites de la fidelidad. La constricción necesaria conduce a interminables divagaciones sentimentales. Y serán estas últimas las que tan a menudo pueden apreciarse también en el conjunto de la novela francesa romántica. No en vano se ha considerado que el Romanticismo es de cuño netamente católico, que su principal argumento es la búsqueda de un absoluto que no parece hallarse en lo terrena y que conlleva acentos melancólicos y abandonos definitivos que desembocan en el suicidio o en la devoción.

Algo así sucede en Volupté, de Sainte-Beuve, publicada en 1834, y en la que puede apreciarse fácilmente la complacencia en el amor prohibido e incapaz de ofrecer posibilidad alguna de realización. Amaury, su protagonista, enamorado de una mujer casa, y a la vez decepcionado frente a la solución que ha tratado de encontrar (la compañía de una coqueta), opta por aferrarse al amor imposible. La firmeza moral de su oponente femenina, su fidelidad al marido, provocan que Amaury se dé por vencido, que abandone el mundo y decida hacerse sacerdote. De poco ha servido la amistad que ella pueda ofrecerle. Tras la fachada del platonismo subyace la necesidad imperiosa de la pasión, que se ha visto relegada y desesperanzada hasta el punto de provocar una deserción del mundo y un intento desesperado de encontrar la plenitud en horizontes más etéreos.

El reverso de la misma moneda lo encontramos en Le lys dans la Vallée (1835), de Balzac: Henriette de Mortsauf trata de resistir a la pasión que en ella ha despertado Félix de Vandenesse y, siguiendo el modelo ya citado, intenta convertirse en su pro-

\footnotetext{
${ }^{5}$ G. Genette, "Le serpent dans la bergerie, introduction à L'Astrée", 10/18, 1964; estudio que también incluye en Figures I, París (Ed. Du Seuil), 1966.

${ }^{6}$ M. Lever, recoge este término y lo utiliza en su obra Romanciers du Grand Siècle, París (Ed. Fayard) 1966, p.70.
} 
tectora, en su madre, en su amiga. Tal es su represión y su resistencia interior que enferma y muere.

Numerosos serán los ejemplos de desenlaces trágicos provocados por un sentimiento fogoso y ahogado por los convencionalismos sociales en la novela francesa decimonónica. Para algunos, se trata de poner en evidencia el peligro que acarrea el amor. La finalidad es, para ellos, prevenir a los lectores, exorcizarlos a través de la lectura. Para otros, se trata de poner en tela de juicio la institución del matrimonio, la dilectio. Y en esta línea se inscribe la inquietud de los moralistas y su preocupación por convencer a las lectoras del modelo de conducta que deben seguir y que, generalmente, es el contrario al que propone la literatura.

$Y$ es que hablar de sexualidad siempre ha resultado difícil y a esa dificultad contribuyó en gran medida la influencia decisiva de la moral cristiana, con su condena y su desprecio del placer. Según Flandrin, durante dieciocho siglos la Iglesia se negó a admitir el amor, salvo castrado y convertido en caridad: como tal, ya no tenía nada que ver con la atracción sexual y sólo aparecía, excepcionalmente, en los debates sobre el matrimonio 7.

La conducta sexual femenina se convirtió durante el siglo XIX, con el acercamiento de la mujer a la lectura y su promoción cultural, en punto de mira preferente. Como secularmente sólo se le había propuesto el modelo de la emotividad, los moralistas se escandalizarán ante los modelos literarios que desvelan para ella apetencias íntimas, todavía más rotundas sin cabe en la novela realista.

El Realismo y su retoño, el Naturalismo, pondrán el dedo en la llaga al denunciar sin tapujos la muy frecuente falta de amor en el matrimonio, la absoluta inoperancia de la dilectio. Sus tramas insisten en resaltar la distancia que separa el deseo y la procreación recomendada por la moral religiosa, que ve en toda expresión de las pulsiones, incluso en el seno de la pareja formalmente constituida, simple pecado o expresión primaria de los instintos más deleznables.

Los novelistas no lo ignoran y su denuncia consiste en poner de relieve los puntos flacos de tal afirmación. Madame Bovary, ejemplo donde los haya de mujer extraviada y la búsqueda de un ideal, será condenada por los defensores del tradicionalismo. Poco importa que su final sea tétrico. Lo relevante es el camino recorrido, el ejemplo de la rebelión, el seguimiento de las leyes del corazón y de la necesaria convención. Los moralistas lo saben y no dudan en procesar a su autor.

Silenciar y acallar la voz de los novelistas, representantes del género literario más leído, se convirtió en tarea principal. Pero conseguirlo no resultaba fácil. No bastaba con prohibir la lectura de ciertas obras; al contrario, esa medida incrementaba su fama y la curiosidad de los lectores. Había que buscar otro método para contrarrestar dicha influencia y la Iglesia encontró uno infalible, al menos en teoría: editar paralelamente otro tipo de novelas, cristianas, edificantes, que pudiesen interesar a las lectoras femeninas, las más expuestas al peligro.

Esta iniciativa, que ya afloró en Francia durante el siglo XVII, irá en aumento a medida que avancen los años y el número de mujeres interesadas por las novelas. Desde los medios eclesiásticos, se denunció el escaso nivel cultural de las jóvenes y, a

${ }^{7}$ J.L. Flandrin, Le sexe et l'Occident, París (Ed. Seuil) 1981, p.105. 
la vez, la pobre calidad moral de las obras que se les ofrecían, tendentes a incrementar su ya natural propensión a la sensiblería.. Los ejemplos propuestos por la literatura, decían los teólogos, no hacían más que alejarlas de sus deberes 'naturales', los de esposa y madre amantísima, que deberían llevar a término tarde o temprano. Para poner freno a la influencia nefasta de las novelas, se crearon en Francia, durante el siglo XIX, dos revistas católicas. La primera, titulada L'Ouvrier, nació en 1861 y su publicación se prolongó hasta 1919. La segunda, llamada Les Veillées des Chaumières comenzó a publicarse en 1877 y verá la luz hasta el año 1998. Ambas pretendían exponer el ideario cristiano y servir así de parapeto frente al empuje de otro tipo de publicaciones. Así lo manifestaba L'Ouvrier, en 1880: En presencia del mal que devora a la sociedad, de esta acumulación de libros perversos, de periódicos deshonestos, de novelas obscenas... nosotros somos conscientes del bien que debemos y podemos hacer ${ }^{8}$.

De la misma época es un conjunto de "Conferencias para Jovencitas" o "Consideraciones sobre ciertos defectos propios de su edad y de su condición", del abad Méchin. La última parte, titulada "La joven lectora de novelas" habla de esa multitud enorme de novelas y folletines...que causan la muerte de tantas almas, sobre todo entre las jóvenes $^{9}$. El abad se preocupa sobre todo por las obras que presentan el sentimiento amoroso como un placer que incita a la tentación y las que denuncian que la mujer es una víctima del matrimonio y consiguen que le tome aversión. Partiendo -dice- de un principio tan falso como destructor, y consistente en decir que Dios ha creado al hombre tal cual es, concluyen lógicamente que debe... dar rienda suelta a todos los sentimientos que se agitan en su corazón ${ }^{10}$.

La contraofensiva católica frente a la literatura poco recomendable comenzó decididamente en Francia con la tentativa de crear una Biblioteca de poetas y novelistas cristianos, una colección de volúmenes baratos, que se fue al traste en pocos meses, en 1853. No obstante, las dos revistas citadas conocieron mejor suerte y en ellas publicaron sus novelas por entregas las autoras que defendían los postulados cristianos. Al mismo tiempo, y para ayudar a seleccionar las obras, las editoriales católicas publicaban regularmente artículos de crítica y una guía de lectura que pervivió hasta el año 1928, dirigida por el abad Bethléem y titulada Novelas para leer y novelas para prohibir. Será en el marco de toda esa inquietud cuando florezca la novela de amor católica.

Se puede rastrear su emergencia a través de los folletines y de las 'entregas' publicadas por L'Ouvrier y Les Veillées des Chaumières ya mencionados y que muy pronto solicitaron colaboradoras femeninas. Esas autoras escriben lo que podría denominarse 'novela familiar', cuyo esquema es muy simple: la existencia apacible de una familia se ve perturbada por el drama que sufre uno de sus miembros, un amor imposible, ilícito, indigno, que le hace caer en la tentación. Pero, frente a él, se yergue el concepto de caridad y, en último extremo, de dilectio, la búsqueda de un paliativo a esa 'desviación', que no es otra que la férrea estructura de un matrimonio estable en el que primen los valores tradicionales y que sea capaz de restablecer el orden perdido.

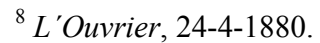

${ }^{9}$ F. Mechin, Conférences aux jeunes filles..., París (Blond et Barral) 1877, p.261.

${ }^{10}$ Idem, pp.288-289.
} 
Entre las colaboradoras que firman esos relatos hay algunos nombres que se presentan bajo pseudónimos. Así sucede con Champol, que en realidad se llamaba M.A. Bastille de Beuverand de la Layère, condesa de Lagrèze. Se sabe también que Jeanne de Coulomb era en realidad Marie de Lagrandval.

Algunas destacaron además por la amplitud de su producción. Tal fue el caso de Maryan (en realidad Marie Cadiou), que escribió 97 relatos entre los años 1878 y 1922, a los que hay que añadir sus múltiples colaboraciones en colecciones como Stella y Foyers-Roman. La fe cristiana inspira e ilustra sus historias de ficción, llenas de pruebas para los protagonistas, pero conducentes a elevar moralmente a los futuros esposos y prepararlos para la más "útil y sagrada" de las obligaciones: la de procrear y formar nuevas almas para las dos patrias, la de aquí abajo y la otra, la infinita, la eterna.

En la novela católica todo se esconde bajo la apariencia de un sentimiento puro y exento de sensualidad. El flechazo existe, pero se trata de una simpatía casi providencial: No puede tratarse desde tal perspectiva de una atracción física, de deseo, sino apenas de una turbación; la sensualidad y la sexualidad no existen ${ }^{11}$.

En una época en la que la educación sentimental de las jóvenes continúa siendo un tema delicado, la familia delega esa responsabilidad en la novela sentimental católica, que se considera puede aportar respuestas a los interrogantes que se plantean las solteras e incluso las casadas. Se trata de proporcionarles una 'sana' visión de la relación amorosa, que canalice sus múltiples inquietudes.

Además de la obra de Maryan, existió una firma destacada en este tipo de publicaciones. Fue la de Delly, pseudónimo de los hermanos Marie y Frédéric Petijean de la Rosière, que escribieron en colaboración más de 100 novelas del "amor permitido", del amor terrenal autorizado y bendecido por la Iglesia. Según Delly, el hombre puede permitirse cierta sensualidad que engloba su proyecto de posesión. No sucede lo mismo con la mujer, que se siente turbada ante la mirada masculina. La disimetría entre ambas conductas no hace más que reflejar la diferenciación real entre las obligaciones requeridas a cada sexo: uno posee y el otro es poseído; uno manda y el otro obedece.

La obra de Delly marcó de alguna manera el fin de la novela de amor católica militante en Francia. Nada mejor para constatar esta realidad que las propias palabras de la jerarquía, que lamenta ${ }^{12}$ que los novelistas hayan asimilado las teorías psicoanalíticas y las hayan puesto al servicio de la denuncia permanente: La última generación de novelistas se muestra particularmente interesada por los problemas de la carne y del espiritu. Freud les ha enseñado mucho; rechazan las timideces y los convencionalismos hipócritas, hasta caer en el extremo opuesto.

Para mantener sus postulados, la crítica católica recurre en el siglo XX a escritores como Paul-André Lesort, y cita una de sus novelas; la primera, titulada Las entranas y los corazones, de 1946, en la que puede resumirse el conjunto de su producción, y que consiste en desarrollar la tesis de que el amor sólo pervive sublimándose. Un

\footnotetext{
${ }^{11}$ E. Constans, Parlez-moi d'amour. Le roman sentimental. Des romans grecs aux collections de l'an 2000, París (Ed. Pulim) 1999, p.204.

${ }^{12}$ J.L. Prevost, La búsqueda de lo absoluto en la novela francesa contemporánea, Madrid (Ed. Razón y Fe) 1967, p.140.
} 
buen ejemplo lo constituye la frase de Ryno de Marigny, personaje central de la obra de Barbey d'Au-revilly, Una vieja amante, que exclama tras los excesos de una pasión adúltera: Esta cosa sin nombre, yo no la llamaría amor.

No obstante, la realidad atestigua que el género católico militante se quedó en mero exponente testimonial. El público lector, en su mayor parte, prefirió recrearse en la literatura libre e imparcial, aquella que preconizaba y exponía la complejidad del sentimiento amoroso en lugar del corsé de la dilectio impuesta y no asumida. Las condiciones y circunstancia de vida de la mujer se transformaron vertiginosamente a partir del siglo XIX, con su incorporación al mercado laboral y a la enseñanza superior. Al tiempo, el feminismo hizo mella en el tejido de la sociedad androcéntrica que había pervivido desde épocas inmemoriales. Nuevos papeles y patrones de conducta liberaron a la mujer de la dependencia secular que había sufrido. Y esto, unido a la consciencia de su propia valía como persona, dio al traste con las propuestas literarias católicas, que no hacían otra cosa que tratar de perpetuar su función reproductora y su consagración por entero al marido, el hogar y los hijos. El avance mismo de la sociedad propició el triunfo indiscutible de la novela laica, procaz o romántica, pero en todo caso próxima a la realidad de la vida.

Incluso los novelistas católicos tuvieron que rendirse ante la evidencia y aquellos que realmente pasaron a engrosar la primera fila, los que destacaron, como Mauriac, se acercaron con valentía a la descripción del casi inevitable fracaso de la pareja instituida por razones de patrimonio o de conveniencia. No bastaba con proponer un ejemplo de familia, no era suficiente con recurrir al concepto de dilectio cuando el amor estaba ausente. Mauriac lo sabía y Thérèse Desqueyroux, su personaje, es un buen ejemplo: Vacía de cariño, desconocedora de la sensualidad, arrinconada en el seno de una familia bien pensante y tradicional, se ve abocada a un acto homicida de liberación que ni ella misma sabría explicar. El final de la noche llega para Thérèse con la constatación de que también ella puede ser amada.

Algo ha cambiado en la perspectiva de la novela cristiana con François Mauriac, algo que indica que resulta muy difícil separar las dos caras del sentimiento amoroso y pretender, al mismo tiempo, que éste no fracase. Su mensaje intenta compensar las dos vertientes en un hábil y acertado equilibrio entre la materia y el espíritu, que ha sido imitado y seguido por no pocos novelistas sin vinculación expresa con ningún credo, pero conscientes de que dicha armonía, no por inevitablemente compleja, debe resultar ineludiblemente necesaria. 